\title{
Remifentanil based anesthetic management for orchiopexy operation in pediatric patient with congenital hypotonia
}

\author{
Konjenital hipotonisi olan çocuk hastada orşiyopeksi ameliyatı için remifentanile \\ dayalı anestezi yönetimi
}

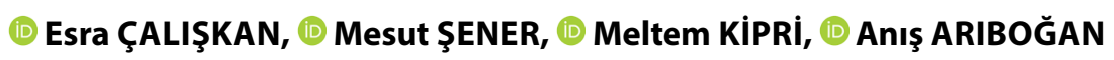

To the Editor,

Congenital hypotonia is a syndrome characterized by a decrease in a muscle tone and power in the affected extremities, craniofacial musculature and trunk in newborn period. ${ }^{[1]}$

Also this syndrom comprises a variety of disorders (include neuromuscular and non-neuromuscular causes) with varying prognosis. ${ }^{[1]}$ The anesthetic management these children are associated with serious problems such as prolonged paralysis, respiratory failure, malign hyperthermia and rarely death. Therefore, it is important that a differential and definitive diagnosis and appropriate anesthetic plan be made.

In this case report, we represented a pediatric patient with congenital hypotonia who underwent orchidopexy operation under remifentanil based general anesthesia.

A 1.5 year-old boy, weighing $12 \mathrm{~kg}$ was admitted to the pediatric surgery clinic and orchiopexy and circumcision operation was planned. He had presented generalized hypotonia and mild motor retardation since birth but, laboratory investigations (muscle enzymes, muscle biopsy and EMG ) were normal. Patient's family was informed about anesthesia related risks.

Preoperatively, he was premedicated by iv $1 \mathrm{mg} \mathrm{kg-1}$ ketamine and $0.01 \mathrm{mg} \mathrm{kg}-1$ atropine. In the operating room pulse oxymeter, 5-channel electrocardiogram, non-invasive blood pressure and bispectral index (BIS) (BIS VISTATM Aspect Medical Systems, Inc., Norwood, MA) were continuously monitored. Thereafter $1 \mu \mathrm{g} \mathrm{kg}-1 \mathrm{~min}-1$ remifentanil infusion (RI) was started. When adequate level of anesthesia was ensured (until BIS decreased to 60 ( $17^{\text {th }}$ minute of RI), laryngeal mask airway was inserted. Ventilation was provided with a mixture of $50 / 50 \%$ oxygen/air combination and anesthesia was maintained with continuous remifentanil infusion. Remifentanil dose was titrated between $0.5-1 \mu \mathrm{g} \mathrm{kg}-1$ min-1 to maintain BIS values between 40 and 60 . The intraoperative course of patient was comfortable and uneventful, did not need supplemental anesthetic agents throughout the 110 minute at the end of surgery. Intraoperatively, heart rate remained at 92-98 bpm, blood pressure range was $97 / 108$ to $47 / 62 \mathrm{~mm} \mathrm{Hg}$, ETCO 2 pressure was $33-$ $35 \mathrm{mmHg}$ and oxygen saturation between $99 \%$ and $100 \%$. He recovered smoothly from anesthesia and transferred to the post-anesthesia care unit without adverse events.

The patient was discharged from the hospital in the second day without any complication after the surgery.

Congenital hypotonia can be classified in two groups; central or peripheral (paralytic-neuromuscular) hypotonia based on their etiologies. ${ }^{[1]}$ In various

Department of Anesthesiology and Reanimation, Başkent University Faculty of Medicine, Ankara, Turkey

Submitted: 13.12.2016 Accepted after revision: 19.01.2018 Available online date: 13.12.2018

Correspondence: Dr. Esra Çalışkan. Başkent Üniversitesi Tip Fakültesi, Anesteziyoloji ve Reanimasyon Anabilim Dalı, Ankara, Turkey.

Phone: + 90 - 322 - 4586868 / 1200 e-mail: esra_ertr@yahoo.com

(- 2018 Turkish Society of Algology 
studies are supported the presence of genetic and metabolic disorders in hypotonic infants. ${ }^{[1]}$ Differencial diagnosis is often complicated, and requires multidisiplinary evaluation.

Hypotonic infant and children phenomenon is a well defined entity for pediatricians, also to evaluation of hypotonic child is one of the most difficult situations that undertaken by the anesthetist. These children often require anesthesia for diagnostic or surgical procedures. Therefore, anesthetic management of these patients is challenging and may cause serious problems to the anesthesiologist especially in children with neuromuscular disorders.

It is considered that serious problems are associated with general anesthesia (such as difficulty in swallowing and breathing, decreased cough reflexes and aspiration, postoperative apnoeic episodes and malign hyperthermia. ${ }^{[2]}$

Also, commonly used anesthetic agents (such as benzodiazepin, propofol, barbiturate) can create potential problems in these patients. These drugs can cause augmented CNS depression and, trigger myotonia especially in patients with myotonic dystrophy. [2,3] Infants with hypotonia due to neuromuscular disease can be affected muscle relaxant and inhalational agents.

The primary objective in the management of hypotonic children was to provide reliable and sufficient surgical anesthesia without serious problems associated with anesthesia.

Remifentanil is seems to be a safe option with favorable pharmacokinetic profile, short duration of action and quick metabolism. Remifentanil infusion rates have been described in adults and children 0.1 to $1 \mu \mathrm{g} . \mathrm{kg} .-1 . \mathrm{min}-1 .{ }^{[4]}$ Catena et al have been described the use of remifentanil as a only one anestetic agent in patients with myotonic dystrophy. ${ }^{\left[{ }^{[5}\right.}$
The efficacy of bispectral index (BIS) monitoring to guide in anesthesia practice has been demonstrated in adults but there are limited data on its feasibility in pediatric patients.

Bannister et al demonstrated that BIS guided anesthetic management was associated with a significant reduction in anesthetic use, earlier emergence and shorter recovery. ${ }^{[6]}$ BIS monitorization could become helpful to measure depth of anesthesia and also to guide dosing of anesthetic drugs.

In this case good and rapid recovery and uneventful postoperative period can be achieved with pure remifentanil based anesthesia associated BIS monitorization.

In conclusion, we consider that remifentanil based anesthesia with BIS monitorization would be a suitable and reliable technique to overcome anestesiarelated risk factors in children with congenital hypotonia.

\section{References}

1. Gowda V, Parr J, Jayawant, S. Evaluation of the floppy infant. Paediatrics and Child Health 2008;18(1):17-21.

2. Ramchandra DS, Anisya V, Gourie-Devi M. Ketamine monoanaesthesia for diagnostic muscle biopsy in neuromuscular disorders in infancy and childhood: floppy infant syndrome. Can J Anaesth 1990;37(4 Pt 1):474-6.

3. Sinclair JL, Reed PW. Risk factors for perioperative adverse events in children with myotonic dystrophy. Pediatric Anesth 2009;19(8):740-7.

4. Fukuda K. Opiods. In: Miller RD, editor. Miller's anesthesia. 7th ed. Philadelphia: Churchill Livingstone Elsevier; 2010. p. 769-824.

5. Catena V, Del Monte DD, Rubini A et al. Anesthesia and myotonic dystrophy (Steinert's syndrome). The role of total intravenous anesthesia with propofol, cisatracurium and remifentanyl. Case report. Minerva Anestesiol 2007;73(9):475-9.

6. Bannister CF, Brosius KK, Sigl JC, Meyer BJ, Sebel PS. The effect of bispectral index monitoring on anesthetic use and recovery in children anesthetized with sevoflurane in nitrous oxide. Anesth Analg 2001;92(4);877-81. 